\title{
A possible effect of an intermediate depth intraslab earthquake on seismic cycles of interplate earthquakes at a subduction zone
}

\author{
Naoyuki Kato \\ Earthquake Research Institute, University of Tokyo, Japan \\ (Received December 3, 2003; Revised May 14, 2004; Accepted May 20, 2004)
}

\begin{abstract}
The effect of static stress perturbations due to an intermediate depth intraslab earthquake on seismic cycles of large interplate earthquakes at a subduction zone is examined through a numerical simulation using a laboratoryderived friction law. The frictional stress on a plate interface in a two-dimensional uniform elastic half-space model is assumed to obey a rate- and state-dependent friction law, and the plate interface is loaded by a steady plate motion, resulting in recurrence of large interplate earthquakes in the model. Static stress perturbations on the plate interface due to an intermediate depth intraslab earthquake with reverse fault type is introduced to the model. This model is set up so as to simulate seismic cycles at the Miyagi-Oki subduction zone, northeastern Honshu, Japan, where a large interplate earthquake is expected to occur and an intraslab earthquake of $\mathrm{M}=7.1$ took place in May, 2003. The simulation result indicates that the static stress changes due to the intraslab earthquake promote slip just below the interplate seismogenic zone, accelerating aseismic sliding there. This aseismic sliding generates stress concentration at the bottom of the seismogenic zone, often advancing the occurrence time of the next interplate earthquake. The shear-stress increases at aseismic slip regions with velocity-strengthening frictional property cannot be held and then aseismic sliding should take place to relax the increased stress. The present simulation result suggests that the promotion of aseismic sliding around the source area is important for evaluating the triggering effects of earthquakes. The conventional Coulomb failure stress approaches to the evaluation of the effect of static stress changes on seismic activity may be insufficient when static stress changes influence aseismic slip rates.
\end{abstract}

Key words: Simulation, friction, seismic cycle, earthquake triggering, aseismic slip.

\section{Introduction}

A large intraslab earthquake $(\mathrm{M}=7.1)$ of reverse fault type occurred on May 26, 2003, off Miyagi prefecture, northeastern Honshu, Japan (e.g., Okada and Hasegawa, 2003). Its location is close to the source area of the hypothetical Miyagi-Oki interplate earthquake (Fig. 1), where interplate earthquakes of $\mathrm{M} \sim 7.5$ are thought to have recurred at an average interval of 37.1 years (Earthquake Research Committee, 2000). The preceding Miyagi-Oki interplate earthquake of $\mathrm{M}=7.4$ in June, 1978 , followed two large intraslab earthquakes of $M=5.8$ in June, 1977 , and of $M=6.7$ in February, 1978 (Takagi, 1980; Choy and Boatwright, 1982). The effect of the intraslab earthquake in May, 2003, on the occurrence of the expected Miyagi-Oki interplate earthquake was examined by calculating static stress changes on the hypothetical source area of the Miyagi-Oki interplate earthquake (e.g., Toda et al., 2003). In these studies the changes in the Coulomb failure stress due to coseismic slip were evaluated to find that the stress changes were too small to trigger the interplate earthquake. Although this approach using the Coulomb failure stress has been successfully applied to explaining seismicity changes following large earthquakes and migration of large earthquakes (e.g., Stein et al., 1997; King

Copy right(c) The Society of Geomagnetism and Earth, Planetary and Space Science (SGEPSS); The Seismological Society of Japan; The Volcanological Society of Japan The Geodetic Society of Japan; The Japanese Society for Planetary Sciences; TERRAPUB. and Cocco, 2001; Toda et al., 2002), the occurrence of aseismic sliding is neglected in these studies. Recent geodetic studies clearly indicate that large earthquakes are often followed by aseismic sliding around the source area of coseismic slip (e.g., Heki et al., 1997; Nishimura et al., 2000). Postseismic sliding was estimated for the 1978 Miyagi-Oki interplate earthquake from leveling and tidal data (Ueda $e t$ al., 2001). Furthermore, Miura et al. (2003) detected with GPS postseismic sliding following a smaller interplate earthquake $(\mathrm{M}=6.3)$ in November, 2002, near the hypothetical source area of the Miyagi-Oki earthquake. In California, the creep rate along the San Andreas fault was changed due to nearby earthquakes as found from creepmeter observations (e.g., Simpson et al., 1988). Creep events may trigger some earthquakes in California (Thurber and Sessions, 1998). A change in aseismic slip rate influences stress field in the neighborhood, possibly triggering earthquakes. Kato and Hirasawa (2000) conducted a numerical simulation study on the effect of an outer rise earthquake on seismic cycles of interplate earthquakes at a subduction zone, assuming rate- and state-dependent friction on the plate interface. They found that the change in aseismic slip rate at the shallower aseismic zone due to the outer rise earthquake significantly affects the occurrence time of the next interplate earthquake.

In the present paper, adopting an approach similar to Kato and Hirasawa (2000), I perform a numerical simulation of seismic cycles of interplate earthquakes at a subduction zone 


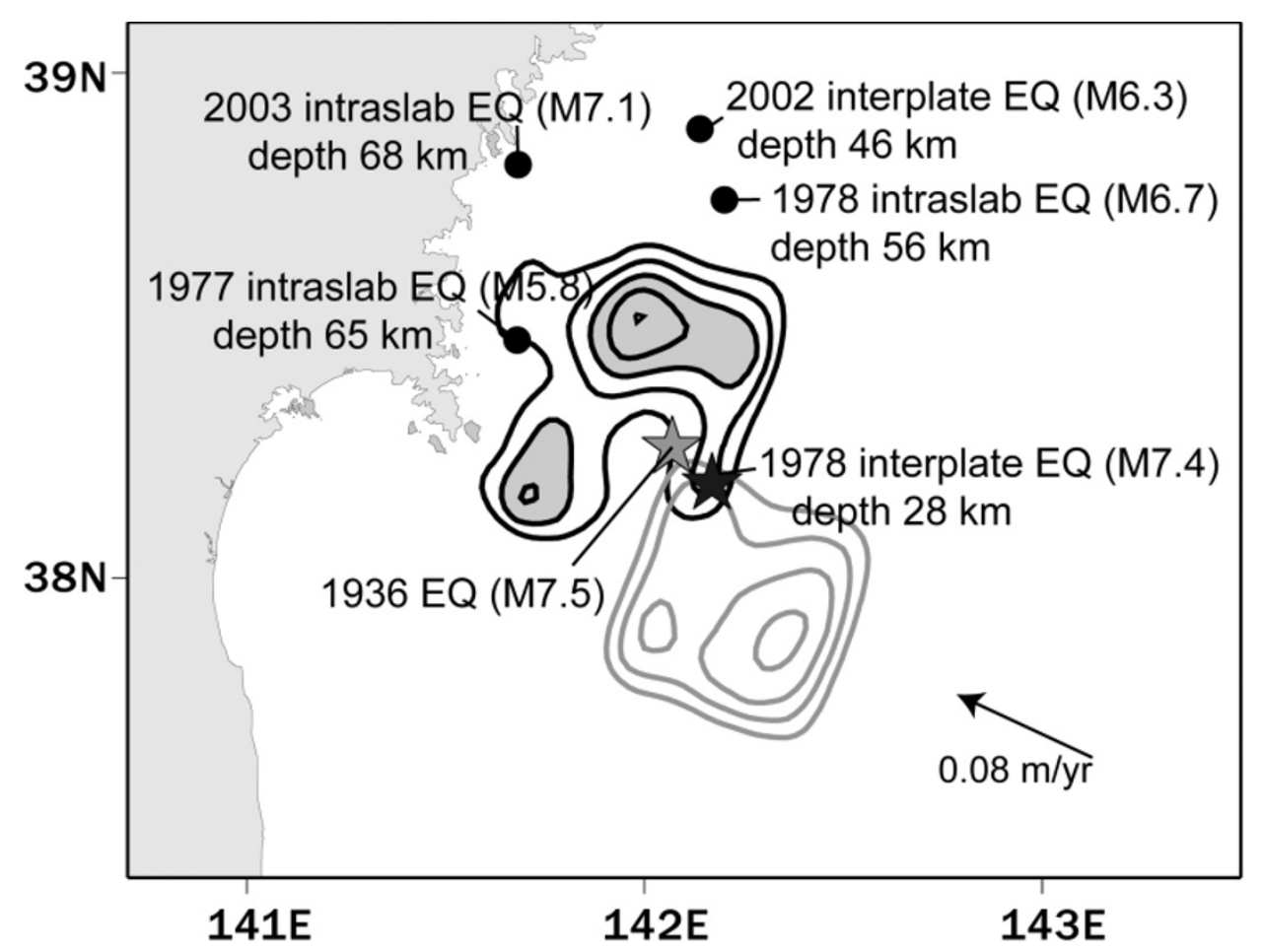

Fig. 1. Map showing the epicenters (starts) and the source areas of the Miyagi-Oki earthquakes of $1936(\mathrm{M}=7.5$; gray) and 1978 (M = 7.4; black) estimated by Yamanaka and Kikuchi (2004), and the epicenters of recent large earthquakes off Miyagi prefecture, northeastern Honshu, Japan.

to investigate the effect of an intermediate depth intraslab earthquake. The model parameters used in the simulation are appropriate for the Miyagi-Oki subduction zone so that the simulation results may give some insight into a forecast for the next Miyagi-Oki interplate earthquake.

\section{The Model for Repeating Interplate Earth- quakes}

We set up a two-dimensional model of a subduction zone with a plate interface in a uniform elastic half-space (Fig. 2). On the plate interface at depths below $85.5 \mathrm{~km}$, I assume stable sliding with a sliding rate equal to the relative plate speed $V_{p l}=0.08 \mathrm{~m} / \mathrm{yr}$ at the Miyagi-Oki subduction zone (Seno et al., 1996). On the shallower parts of the plate interface, the frictional stress complies with a rate- and statedependent friction law, which was developed by Dieterich (1979) and Ruina (1983) on the basis of experimental results of rock friction and was used in simulation studies of seismic cycles by many authors (e.g., Tse and Rice, 1986; Stuart, 1988; Kato and Hirasawa, 2000; Kuroki et al., 2002).

The plate interface where the friction law is assumed is divided into a number of cells each with uniform slip. The shear stress $\tau_{i}$ and the normal stress $\sigma_{i}$ acting at the center of the $i$ th cell are written by

$$
\begin{aligned}
\tau_{i} & =\sum_{j} K_{i j}\left(u_{j}-V_{p l} t\right)+P_{i}-\frac{G}{2 \beta} \frac{d u_{i}}{d t}, \\
\sigma_{i} & =\sum_{j} J_{i j}\left(u_{j}-V_{p l} t\right)+\sigma_{i}^{i n i t}+Q_{i},
\end{aligned}
$$

where $K_{i j}$ and $J_{i j}$ are static shear and normal stresses, respectively, at the $i$ th cell due to unit slip on the $j$ th cell and given theoretically by Rani and Singh (1992), $u_{j}$ is the slip amount on the $j$ th cell, $\sigma_{i}^{i n i t}$ is the initial normal stress, $P_{i}$ and $Q_{i}$ are the shear and normal stresses caused by an intraslab earthquake, $G$ is rigidity, and $\beta$ is the $S$-wave speed of the medium. The third term on the right-hand side of (1) is introduced to represent shear-stress reduction during seismic slip. This enables us to simulate quasi-dynamic high-speed seismic rupture (Rice, 1993).

There are several versions of rate- and state-dependent friction law. In this study I use the composite law proposed by Kato and Tullis $(2001,2003)$ because it better fits experimental data of rock friction at a wide range of conditions than the other laws. The frictional stress $\tau$ is expressed by

$$
\begin{aligned}
& \tau=\mu \sigma, \\
& \mu=\mu_{*}+a \ln \left(V / V_{*}\right)+b \ln \left(V_{*} \theta_{L}\right), \\
& \frac{d \theta}{d t}=\exp \left(-\frac{V}{V_{c}}\right)-\left(\frac{V \theta}{L}\right) \ln \left(\frac{V \theta}{L}\right),
\end{aligned}
$$

where $\mu$ is a friction coefficient, $\theta$ is a state variable representing a contact state of fault surfaces or an internal structure of a gouge zone between fault surfaces, $\mu_{*}, a, b, L$ and $V_{c}$ are constants. $V_{*}$ is arbitrarily chosen reference velocity and is equal to $V_{p l}$ in this study. $\mu_{*}$ is the friction coefficient when $V=V_{*}$ and $\theta=L / V_{*}$ and is assumed to be 0.6 in the present model. $V_{c}$ is taken to be $10^{-8} \mathrm{~m} / \mathrm{s}$ following Kato and Tullis $(2001,2003)$. Friction parameters $a, b$ and $L$ control the sliding behavior of a fault. The steady-state friction coefficient $\mu_{s s}$ may be defined for $d \theta / d t=0$, and $\mu_{s s}$ shows velocity weakening for $a-b<0$ and velocity strengthening for $a-b>0$. For velocity-weakening friction $(a-b<0)$, the shear strength decreases with an increase in sliding velocity, leading to unstable (seismic) slip. On the other hand, for velocity-strengthening friction $(a-b>0)$, aseismic sliding 


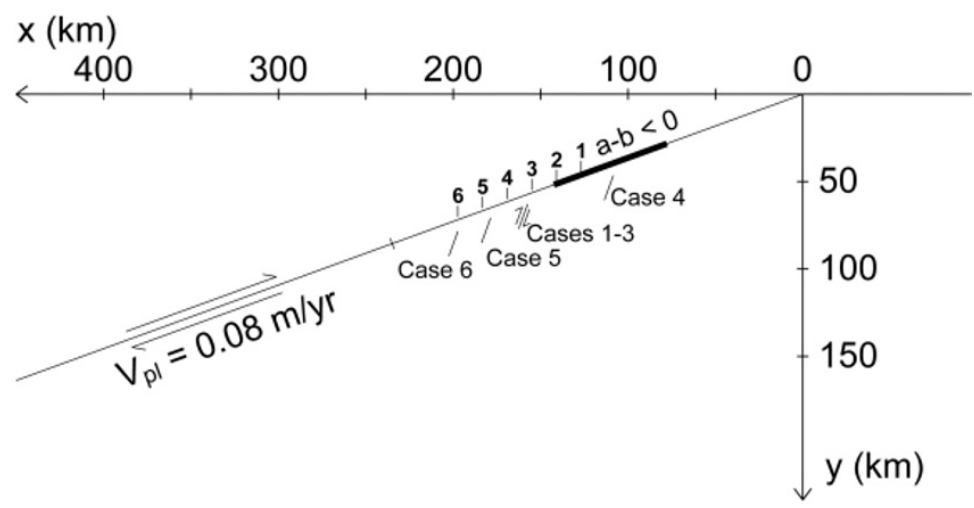

Fig. 2. Two-dimensional model of a subduction zone for the present numerical simulation. A straight fault with a dip angle of $20^{\circ}$ is regarded as a plate interface. Stable sliding with a sliding rate of $0.08 \mathrm{~m} / \mathrm{yr}$ is assumed on the plate interface deeper than $85.5 \mathrm{~km}$, while frictional stress following a rateand state-dependent friction law is applied on the shallower part of the plate interface. The thick-line part indicates the region with velocity-weakening $(a-b<0)$ frictional property, where seismic slip may take place. Points 1 to 6 are observation points of slip histories in Figs. 10 and 11 .

occurs. From a theoretical stability analysis with a singledegree-of-freedom spring block system, Ruina (1983) indicated that unstable slip may occur when $a-b<0$ and the spring stiffness is smaller than the critical stiffness given by

$$
k_{c}=(b-a) \sigma / L
$$

For a finite length fault in an elastic medium, an effective stiffness may be defined by the ratio of slip induced shearstress change $\Delta \tau$ to slip amount $\Delta u: k^{\text {eff }}=\Delta \tau / \Delta u$ (e.g., Dieterich, 1992). For an in-plane shear crack in a Poission solid, $k^{e f f}$ is given by

$$
k^{e f f}=4 G / 3 l
$$

where $l$ is the length of the fault. When $k^{e f f}$ is equal to $k_{c}$, the fault length at this time gives the minimum fault length $h^{*}$ for the occurrence of unstable slip:

$$
h^{*}=\frac{4}{3} \frac{G}{(b-a) \sigma} L .
$$

Rice (1993) showed that the cell size $h$ in numerical computations must be sufficiently smaller than $h^{*}$ to avoid numerical instability. In the present simulation $h$ ranges from $50 \mathrm{~m}$ to $1 \mathrm{~km}$, and $h / h^{*}$ is always smaller than 0.01 .

The variation with depth of $a$ and $b$ assumed in the present model is shown in Fig. 3, and $L=10 \mathrm{~mm}$ independent of depth. Laboratory studies indicate that $a$ and $b$ depend on experimental conditions such as rock type, gouge material between sliding surfaces, and temperature (e.g., Marone, 1998). The depth profile in Fig. 3 is similar to laboratory data (e.g., Blanpied et al., 1995) and to those assumed in numerical simulations of seismic cycles at subduction zones (e.g., Stuart, 1988; Kato and Hirasawa, 2000; Kuroki et al., 2002). The assumed frictional property shows velocity weakening $(a-b<0)$ at depths between $28.33 \mathrm{~km}$ and $51.82 \mathrm{~km}$, which is approximately consistent with the source region of the 1978 Miyagi-Oki interplate earthquake estimated by Aida (1978) and Seno et al. (1980). Off Miyagi prefecture, large earthquakes have occurred also at shallower parts of the plate interface (Kawakatsu and Seno, 1983; Earthquake Research Committee, 2000), and therefore there must be another $a-b<0$ region at shallower parts. In this study,

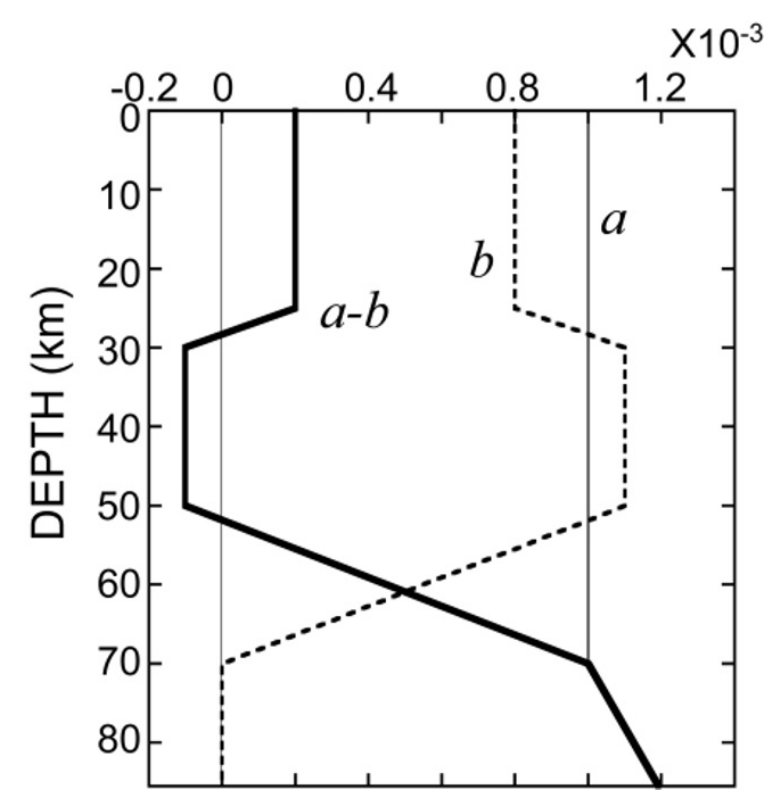

Fig. 3. The variation with depth of friction parameters $a, b$, and $a-b$ assumed in the present model.

however, I neglect this shallower sesimogenic zone for simplicity.

The lithostatic pressure and the hydrostatic pore pressure are assumed for the initial effective normal stress $\sigma^{\text {init }}$ : $\sigma^{\text {init }}=\left(\rho-\rho_{w}\right) g y$, where $\rho=2.8 \times 10^{3} \mathrm{~kg} / \mathrm{m}^{3}, \rho_{w}=$ $1.0 \times 10^{3} \mathrm{~kg} / \mathrm{m}^{3}, g=9.8 \mathrm{~m} / \mathrm{s}^{2}$, and $y$ is depth. Elastic property of the medium is as follows: the rigidity $G=30$ GPa, the Poission ratio $v=0.25$, and the $S$-wave speed $\beta=3.27 \mathrm{~km} / \mathrm{s}$.

The initial condition is that stable sliding with a sliding rate of $0.1 V_{p l}$ occurs on the entire plate interface. Sliding process is simulated by numerically solving (1)-(5) with a Runge-Kutta method (Press et al., 1992). After transitional sliding behavior caused by the artificial initial condition, simulated interplate earthquakes regularly occur at a recurrence interval of 36.9 years, which agrees well with the estimated recurrence interval 37.1 years of large interplate earthquakes off Miyagi prefecture from last six earth- 


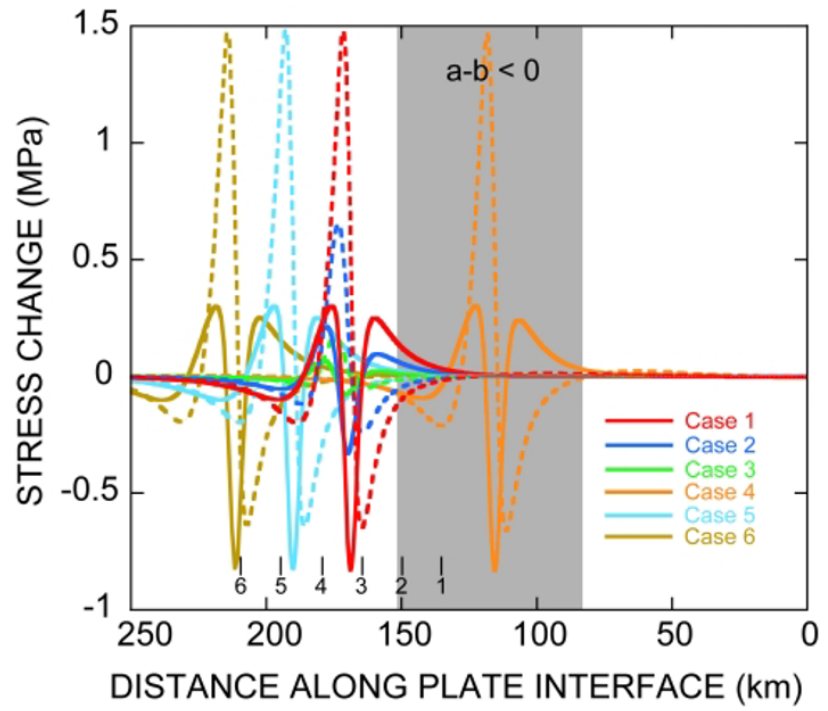

Fig. 4. Static shear (solid lines) and normal stress (dotted lines) changes on the plate interface due to intraslab earthquakes assumed in the present simulation (Table 1). The distance along the plate interface is measured from the trench. The shaded area indicates the seismogenic region on a plate interface with velocity-weakening $(a-b<0)$ frictional property. Numerals 1 to 6 denote the locations of observation points of slip in Figs. 10 and 11.

quakes (Earthquake Research Committee, 2000). The average seismic slip amount at the $a-b<0$ region of each simulated earthquake is $2.4 \mathrm{~m}$, where seismic slip is defined for simplicity slip with slip rate equal to or greater than 10 $\mathrm{mm} / \mathrm{s}$. This cosesimic slip amount is roughly consistent with 1.9-2.4 $\mathrm{m}$ of the 1978 Miyagi-Oki interplate earthquake estimated by Seno et al. (1980) and $2.3 \mathrm{~m}$ at an asperity by Yamanaka and Kikuchi (2004) from seismic wave modeling or $2.0 \mathrm{~m}$ from tsunami wave modeling by Aida (1978).

\section{The Effect of an Intraslab Earthquake \\ 3.1 Simulation results}

The effect of an intermediate depth intraslab earthquake is examined by imposing static stress perturbation caused by the earthquake to the seismic cycle simulation of interplate earthquakes. The static shear and normal stress changes are expressed by $P_{i}$ and $Q_{i}$ in (1) and (2), respectively. The source parameters of intraslab earthquakes with the dip angle of $70^{\circ}$ used in the simulation are shown in Table 1 , and the fault locations are illustrated in Fig. 2. The hypocenter is located at the midpoint of the fault for each case, and pure dip slip is assumed to be uniform over the fault. The distances between the hypocenters and the plate interface are the same for all the cases. The assumed parameters of Case 1 are similar to those of the $\mathrm{M}=7.1$ MiyagiOki intraslab earthquake of May 26, 2003 (e.g., Okada and Hasegawa, 2003; Yamanaka and Kikuchi, 2003). Figure 4 shows static shear and normal stresses on the plate interface caused by the intraslab earthquakes in Table 1, where shear stress in slip direction and compression of normal stress are taken to be positive. These stresses are calculated by using analytical expressions for stresses due to dip slip (Rani and Singh, 1992). The average stress drop at the $a-b<$ 0 region on the plate interface of the simulated interplate

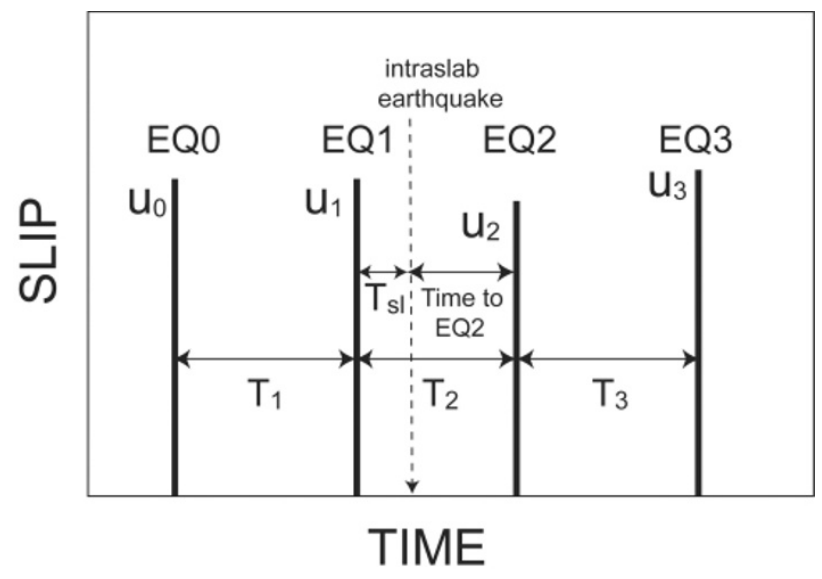

Fig. 5. Schematic history of coseismic slip on the plate interface. $T_{i}$ is the time interval between $\mathrm{EQ}(i-1)$ and $\mathrm{EQ}(i)$, and $u_{i}$ is the coseismic slip amount of EQ $(i)$. An intraslab earthquake takes place at the time $T_{s l}$ from the occurrence of EQ1.

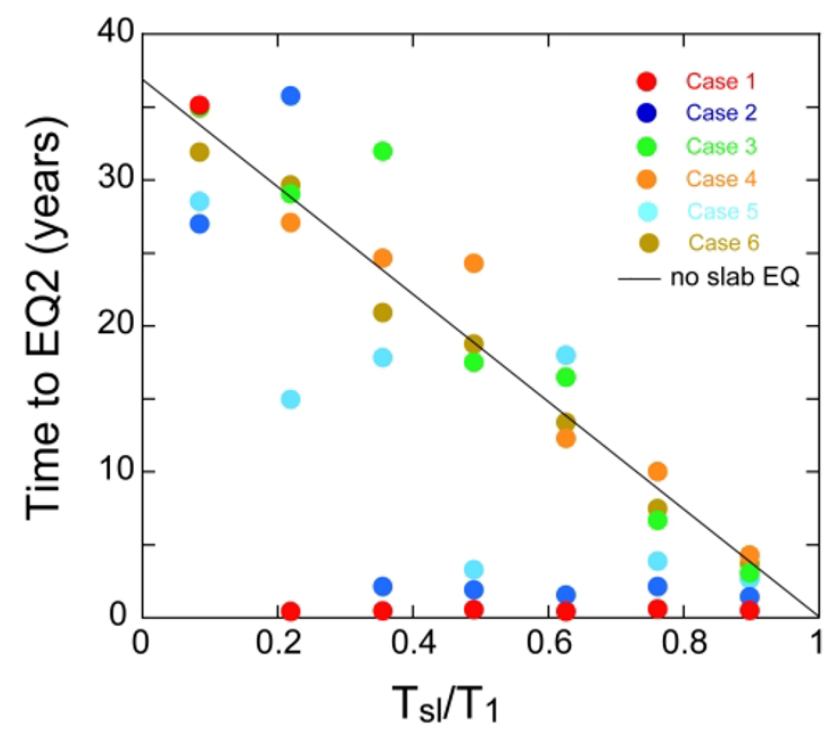

Fig. 6. The time interval from the occurrence of an intraslab earthquake to the next interplate earthquake EQ2 versus $T_{s l} / T_{1}$. A straight solid line indicates the time if the occurrence time of EQ2 is not affected by the intraslab earthquake.

earthquake is 1.4 MPa. For Cases 1, 2, 3, 5, and 6, the static stress changes at the $a-b<0$ region are much smaller than the stress drop of the interplate earthquake, because the source locations are under the deeper extension of the seismogenic plate interface. For Case 4 , the static stress changes are relatively large at the $a-b<0$ region because the intraslab earthquake in Case 4 is just under the $a-b<0$ region. It should be remarked that the 2003 Miyagi-Oki intraslab earthquake is not located at a simply deeper extension of the source area of the 1978 Miyagi-Oki interplate earthquake as shown in Fig. 1. Their epicenters are separated about $30 \mathrm{~km}$ in the direction parallel to the trench axis. Accordingly, the stress changes for Case 1 in Fig. 4 may be too large to evaluate the effect of the 2003 MiyagiOki intraslab earthquake on the next Miyagi-Oki interplate earthquake. This should be taken into consideration in the 
Table 1. Parameters of intraslab earthquakes in simulations.

\begin{tabular}{ccccc}
\hline Model & $x(\mathrm{~km})$ & $y(\mathrm{~km})$ & fault length $(\mathrm{km})$ & slip $(\mathrm{m})$ \\
\hline 1 & 160.0 & 70.0 & 15.0 & 1.0 \\
2 & 160.0 & 70.0 & 10.0 & 0.667 \\
3 & 160.0 & 70.0 & 5.0 & 0.333 \\
4 & 110.0 & 51.80 & 15.0 & 1.0 \\
5 & 180.0 & 77.28 & 15.0 & 1.0 \\
6 & 200.0 & 84.56 & 15.0 & 1.0 \\
\hline
\end{tabular}

$x, y$; the location of midpoint of the fault in the $x y$-coordinates in Fig. 2 .

interpretation of the simulation result.

The stress changes due to an intraslab earthquake are introduced in the seismic cycle simulation for interplate earthquakes. Figure 5 schematically shows the history of interplate earthquakes. The simulated interplate earthquakes are named EQ0, EQ1, EQ2, and so forth. $u_{i}$ is the coseismic slip amount of $\mathrm{EQ}(i)$, where coseismic slip amount is the average one over the $a-b<0$ region. The time interval between $\mathrm{EQ}(i-1)$ and $\mathrm{EQ}(i)$ is denoted by $T_{i}$. At time $T_{s l}$ from EQ1, an intraslab earthquake is generated. As shown in the preceding section, large interplate earthquakes regularly occur in the simulation before the intraplate earthquake and $T_{1}=36.9$ years and $u_{0}=u_{1}=2.4 \mathrm{~m}$. The stress perturbations due to an intraslab earthquake may disturb the regular occurrence of interplate earthquakes. I measure the time to EQ2 from the intraslab earthquake, time intervals $T_{2}$ and $T_{3}$, and the coseismic slip amounts $u_{2}$ and $u_{3}$ to examine the effect of an intraslab earthquake, varying $T_{s l}$ to see the time dependent effect since frictional strength is dependent on time.

The time to EQ2 from the occurrence of an intraslab earthquake is plotted against $T_{s l} / T_{1}$ in Fig. 6, where the solid line indicates the time to EQ2 for no intraslab earthquake $\left(T_{2}=\right.$ $\left.T_{1}\right)$. For $T_{s l} / T_{1}>\sim 0.22$ in Case 1 and for $T_{s l} / T_{1}>\sim 0.36$ in Case 2, the times to EQ2 from the occurrence of an intraslab earthquake are about 0.5 years and 2 years, respectively, independent of $T_{s l} / T_{1}$. In Cases 1 and 2, an intraslab earthquake increases shear stress at the deeper end of seismogenic zone with velocity-weakening $(a-b<0)$ frictional property, where an interplate earthquake is nucleated, and at a region just below the seismogenic zone (Fig. 4). The shear-stress increase at this region may affect the nucleation of seismic rupture of an interplate earthquake as discussed in the next subsection, resulting in significantly earlier occurrence of the next interplate earthquake (EQ2). For $T_{s l} / T_{1}=0.08$ in Case 1 and $T_{s l} / T_{1}=0.22$ in Case 2, the occurrence time of the next interplate earthquake (EQ2) from an intraslab earthquake is delayed in spite of the shear-stress increase at the nucleation region of an interplate earthquake. The cause of this delay will be discussed also in the next subsection. In Case 3, where the location of an intraslab earthquake is the same as those for Cases 1 and 2 but with a smaller magnitude, the time to EQ2 from an intraslab earthquake is scattered around the no intraslab earthquake line, that is $T_{2} \approx T_{1}$, probably because the stress changes due to an intraslab earthquake are too small to significantly affect the next interplate earthquake. In Case 4, the perturbations in stresses due to an intraslab earthquake are relatively large

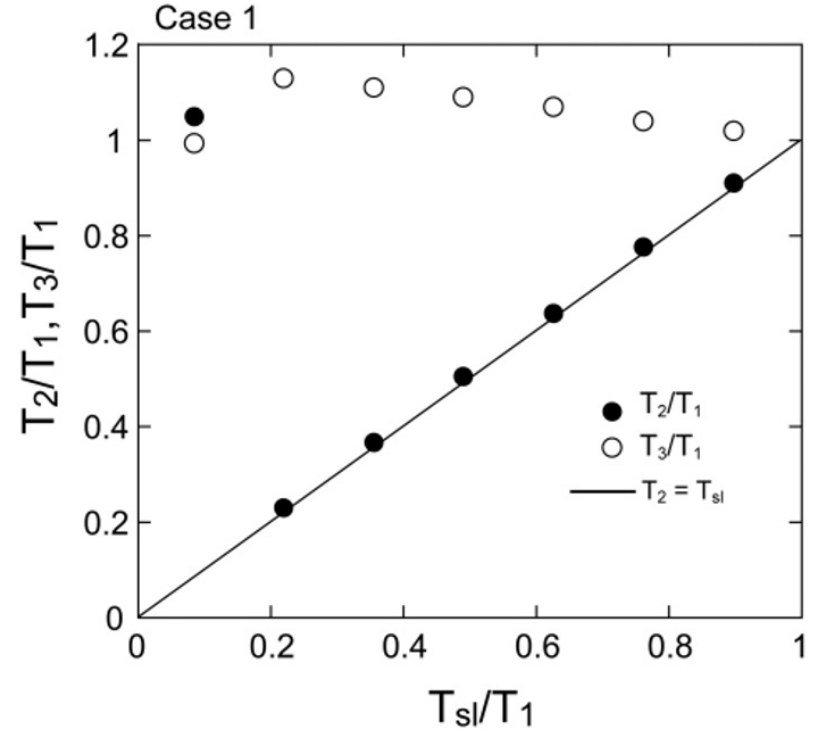

Fig. 7. The time intervals of successive interplate earthquakes $T_{2}$ (solid circles) and $T_{3}$ (open circles), normalized by $T_{1}$, versus the occurrence time of an intraslab earthquake $T_{s l}$ normalized by $T_{1}$ for Case 1 .

at the interplate seismogenic zone with velocity-weakening frictional property (Fig. 4) because the intraslab earthquake is located just under the seismogenic zone (Fig. 2). The peak shear stress amounts to about $0.3 \mathrm{MPa}$, about $20 \%$ of the average stress drop of EQ1. However, the time to EQ2 from the occurrence of an intraslab earthquake in Case 4 deviates little from the line of no effect of intraslab earthquake as shown in Fig. 6. This is probably because the spatial distribution of the stress changes is not uniform and aseismic sliding is not promoted by the stress changes at the locked plate interface with velocity-weakening $(a-b<0)$ frictional property. In Cases 5 and 6, where the locations of intraslab earthquakes are deeper than that of Case 1 and accordingly the stress changes at the nucleation region of an interplate earthquake are smaller than those for Case 1, the effect on the occurrence time of EQ2 is smaller than that for Case 1. These results suggest that the stress changes around the nucleation region of an interplate earthquake are important for triggering of an interplate earthquake.

To see the effect of an intraslab earthquake on the occurrence times of EQ2 and EQ3 for Case 1, I plot $T_{2} / T_{1}$ and $T_{3} / T_{1}$ versus $T_{s l} / T_{1}$ in Fig. 7 . For $T_{s l} / T_{1}>\sim 0.2, T_{2} / T_{1}$ is close to $T_{s l} / T_{1}$ because EQ2 occurs about 0.5 years after the occurrence of an intraslab earthquake in Case 1 , as seen in 


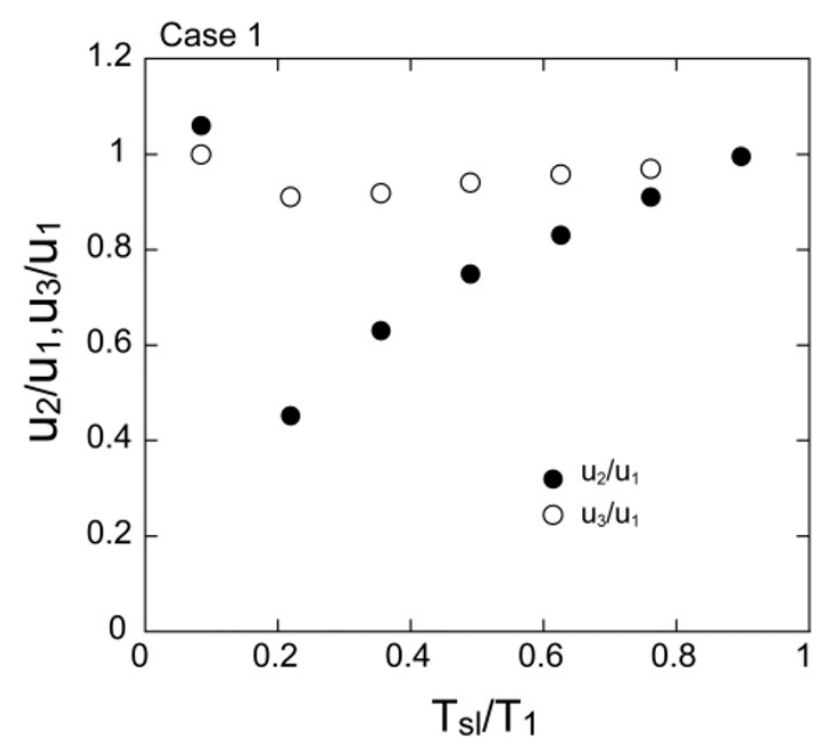

Fig. 8. The average coseismic slip amounts $u_{2}$ (solid circles) and $u_{3}$ (open circles) of EQ2 and EQ3, respectively, normalized by the average coseismic slip of EQ1 $u_{1}$, versus the occurrence time of an intraslab earthquake $T_{s l}$ normalized by $T_{1}$ for Case 1 .

Fig. 6. On the other hand, $T_{3} / T_{1}$ is always close to 1 independent of $T_{s l} / T_{1}$, indicating that an intraslab earthquake significantly affects only the next interplate earthquake (EQ2). The effect of an intraslab earthquake on the magnitudes of EQ2 and EQ3 is shown in Fig. 8, where $u_{2} / u_{1}$ and $u_{3} / u_{1}$ are plotted against $T_{s l} / T_{1}$ for Case 1 . Comparing Fig. 8 with Fig. 7 , I find that $u_{2} / u_{1}$ correlates with $T_{2} / T_{1}$. When EQ2 occurs earlier than expected due to the occurrence of an intraslab earthquake, the coseismic slip of EQ2 becomes smaller than usual. Figure 8 further indicates that $u_{3}$ is close to $u_{1}$ independent of $T_{s l} / T_{1}$, corresponding to $u_{3} \approx u_{1}$. Although I show relations between $T_{2} / T_{1}$ or $T_{3} / T_{1}$ and $T_{s l} / T_{1}$ and between $u_{2} / u_{1}$ or $u_{3} / u_{1}$ and $T_{s l} / T_{1}$ for only Case 1 to avoid redundancy, the characteristics of EQ3 are similar to those of EQ1 $\left(T_{3} / T_{1} \approx 1\right.$ and $\left.u_{3} / u_{1} \approx 1\right)$ for all the cases.

To see the correlation between $u_{2} / u_{1}$ and $T_{2} / T_{1}$ more clearly, I plot $u_{2} / u_{1}$ versus $T_{2} / T_{1}$ in Fig. 9 for all simulation results (Cases 1 to 6 ), indicating that the positive correlation is established for all the cases. This is because the accumulated strain energy in the source volume at the occurrence time of EQ2 should be roughly proportional to $T_{2}$. The positive correlation between $u_{2} / u_{1}$ and $T_{2} / T_{1}$ indicates that the occurrence of EQ2 approximately obeys the slip predictable model, in which the slip of the next earthquake can be predicted from the lapse time from the preceding earthquake (Shimazaki and Nakata, 1980). The stress perturbations due to an intraslab earthquake do not affect the whole strain energy of the source volume of a large interplate earthquake but affect sliding behavior of the nucleation region and the occurrence time of the interplate earthquake.

In the present study I examine cases where aseismic sliding is enhanced by stress perturbations. It is remarked that the occurrence time of the next interplate earthquake may be delayed when aseismic sliding is suppressed by shear-stress decrease due to a nearby earthquake. This is demonstrated by Kato and Hirasawa (2000) in their numerical simulation

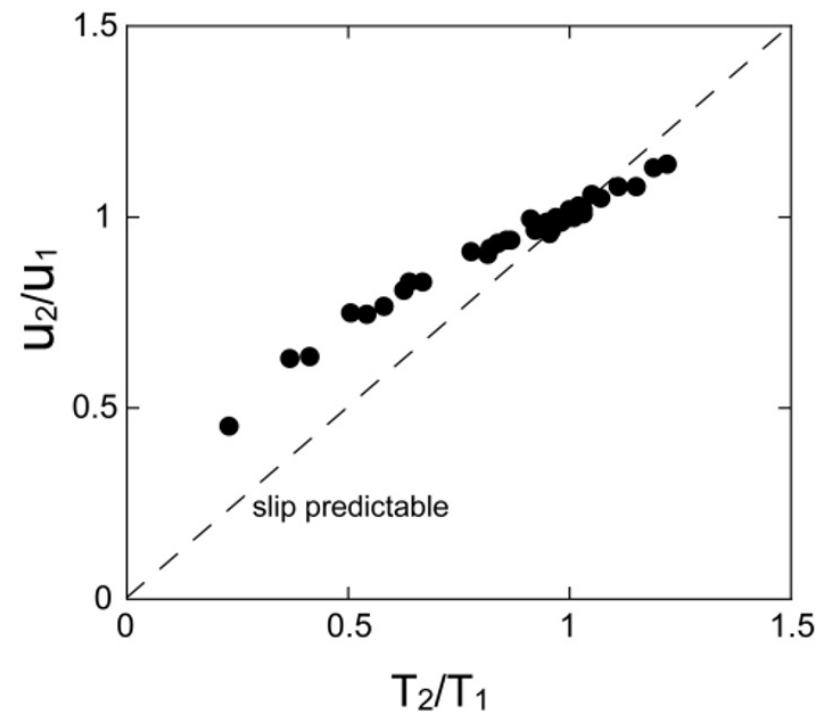

Fig. 9. The relative slip amount $u_{2} / u_{1}$ of EQ2 versus the relative recurrence interval $T_{2} / T_{1}$ for Cases 1 to 6 . The dotted line indicates the theoretical relation of the slip predictable model.

for the effect of an outer rise earthquake on interplate earthquake cycles.

I perform some additional numerical simulations with different values of $a-b$ in the seismogenic zone or different $L$ to confirm that the simulation results are qualitatively unchanged. The stress perturbations due to an intraslab earthquake usually advance the occurrence time of the next interplate earthquake and reduce its magnitude. For example, in the case of $L=20 \mathrm{~mm}$ with the same variations with depth of $a$ and $b$ as those in Fig. 3, the time to the next interplate earthquake from the occurrence of an intraslab earthquake is generally longer than that for $L=10 \mathrm{~mm}$ (Case 1). This is probably because the critical nucleation zone size $h^{*}$ for an earthquake is longer (Eq. (8)) and an earthquake rupture is harder to occur for a larger $L$. For still larger $L$, the nucleation depth of an earthquake rupture tends to be shallower (Kato and Seno, 2003) and then the distance from the intraslab earthquake to the nucleation point of an interplate earthquake becomes longer. Accordingly, the effect of an intermediate-depth intraslab earthquake may be smaller for very large $L$.

\subsection{Aseismic sliding induced by an intraslab earth- quake}

To investigate why the occurrence time of EQ2 is advanced or delayed due to the effect of an intraslab earthquake, I examine sliding behavior on the plate interface at the occurrence of an intraslab earthquake. Figure 10 shows slip histories at six points (Fig. 2) for $T_{s l} / T_{1}=0.22$ in Case 1. Slip is accelerated by the intraslab earthquake at Points 2 , 3 , and 4 , where the shear stress on the plate interface is increased and the normal stress is decreased as shown in Fig. 4. Point 2 is located near the deeper end of the seismogenic velocity-weakening $(a-b<0)$ region, and Points 3 and 4 are in the velocity-strengthening $(a-b>0)$ region just below the seismogenic region. When shear stress is increased in a velocity-strengthening region, aseismic sliding occurs with a possible time delay to relax the increased stress. This 


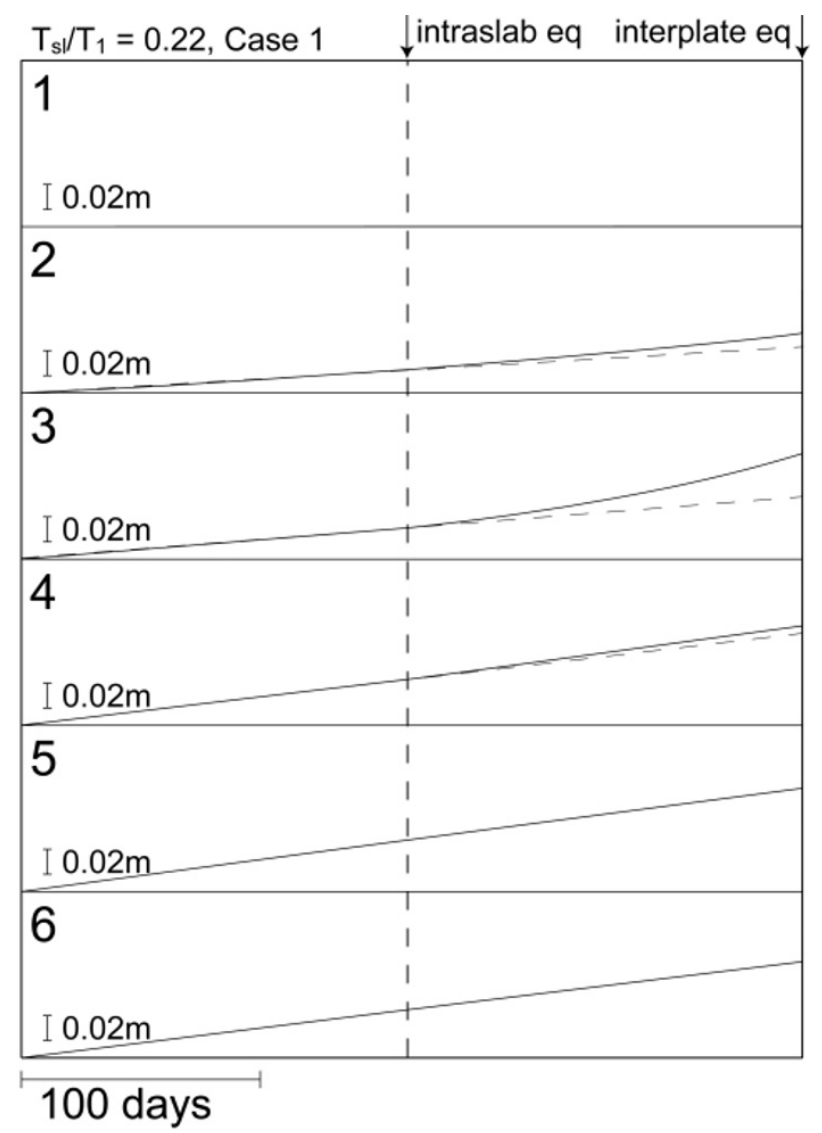

Fig. 10. Simulated slip histories at six points on the plate interface (Figs. 2 and 4) for a time interval before and after the occurrence of an intraslab earthquake for $T_{s l} / T_{1}=0.22$ in Case 1 .

aseismic sliding should increase shear stress in neighboring regions with velocity-weakening frictional property, possibly promoting the occurrence of an interplate earthquake in the velocity-weakening region. This is the cause of significant advance of the occurrence time of interplate earthquake (EQ2) for $T_{s l} / T_{1}>\sim 0.2$ in Case 1 and $T_{s l} / T_{1}>\sim 0.3$ in Case 2. For this mechanism, the promotion of aseismic sliding in a region next to a seismogenic region with velocityweakening frictional property is important, because the accelerating aseismic sliding may generate stress concentration for the occurrence of seismic slip. This effect of loading by aseismic sliding on the earthquake promotion may be smaller when the shear-stress increase is small (Case 3), the shear-stress increase appears in the locked seismogenic region (Case 4), or the region of shear-stress increase is far from the seismogenic region (Cases 5 and 6).

Figure 11 shows slip histories at six points on the plate interface (Figs. 2 and 4) at the occurrence of intraslab earthquake for $T_{s l} / T_{1}=0.08$ in Case 1 , where the occurrence time of the next interplate earthquake (EQ2) is delayed $\left(T_{2}=\right.$ 38.6 years). The shear-stress increase due to the intraslab earthquake increases aseismic slip rates at Points 2, 3, and 4. This process is similar to that for $T_{s l} / T_{1}=0.22$ in Case 1 (Fig. 10). However, for $T_{s l} / T_{1}=0.08$ an interplate earthquake is not triggered by this aseismic sliding, probably because the lapse time from the preceding interplate earthquake (EQ1) is too short to accumulate strain energy for an inter-

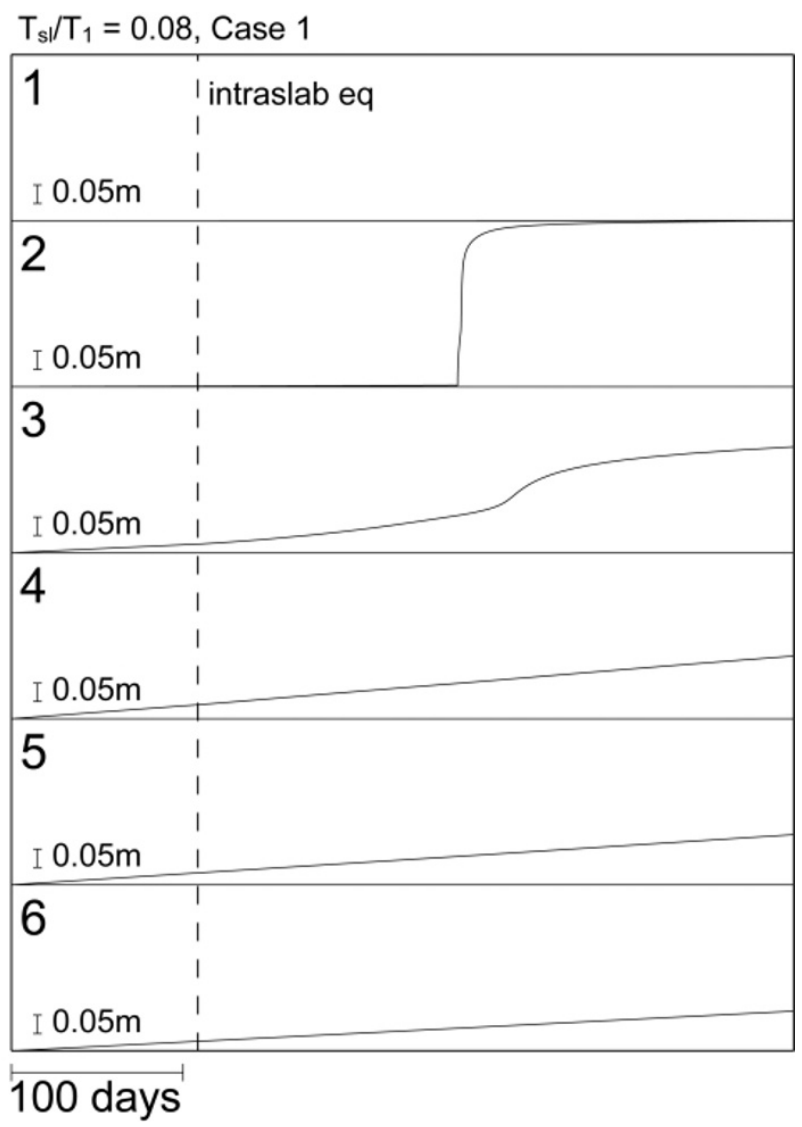

Fig. 11. Simulated slip histories at six points on the plate interface (Figs. 2 and 4) for a time interval before and after the occurrence of an intraslab earthquake for $T_{s l} / T_{1}=0.08$ in Case 1 .

plate earthquake. Instead, an episodic aseismic slip event occurs around the deeper end of the seismogenic velocityweakening $(a-b<0)$ region (Point 2 in Fig. 11), partially relaxing strain energy stored in the region. This partial energy release is probably the cause of the delay of the next interplate earthquake. It should be noted that no episodic aseismic slip event occurs during an interseismic period in the present model when the stress perturbations due to an intraslab earthquake are not introduced. Kato and Hirasawa (1999) showed that episodic aseismic slip events may occur when nonuniform frictional property exists on an plate interface.

The above discussion using simulated slip histories before and after the occurrence of an intraslab earthquake indicates that induced aseismic sliding by an intraslab earthquake may significantly affect the occurrence of an interplate earthquake. When shear stress is increased at a region with velocity-strengthening $(a-b>0)$ frictional property, the increased shear stress cannot be held for a long time but aseismic sliding occurs with a possible time delay to relax the shear stress. If the region of induced aseismic sliding is close to a seismogenic zone, it may cause stress concentration at a seismogenic zone, possibly resulting in the trigger of the next interplate earthquake. On the other hand, when shear stress is increased at a region with velocity-weakening $(a-b<0)$ frictional property, significant aseismic sliding may not occur because the plate interface is strongly locked 
at the region. In this case, the effect of stress perturbation on the occurrence of the next interplate earthquake is relatively small, as shown for Case 4 in Fig. 6, except when the induced shear-stress change is close to the stress drop of an interplate earthquake or when the accumulated stress there is already close to the failure stress.

\section{Summary and Discussion}

Numerical simulation using a rate- and state-dependent friction law is done for understanding the effect of an intermediate depth intraslab earthquake on seismic cycles of interplate earthquakes at a subduction zone. The simulation result indicates that the occurrence time of the next interplate earthquake is significantly advanced when shear stress is increased around the region of slip nucleation of an interplate earthquake. Shear-stress increase at a region of velocitystrengthening frictional property may be important because the increased shear stress cannot be held for a long time but aseismic sliding should take place to relax the stress, increasing shear stress at the neighboring locked regions. When the occurrence time of an interplate earthquake is advanced due to the stress perturbations by an intraslab earthquake, the magnitude of the interplate earthquake tends to be small. This suggests that the recurrence of interplate earthquakes obeys the slip predictable model rather than the time predictable model when stress perturbations due to nearby earthquakes control the occurrence times of interplate earthquakes.

Mogi (1973) reported that large compressional deep focus earthquakes sometimes preceded large interplate earthquakes at western Pacific subduction zones. He speculated that a deep compressional earthquake pulls the slab, resulting in the promotion of thrust of plate interface and triggering an interplate earthquake. However, the present simulation suggests that the occurrence of an interplate earthquake is significantly affected only when a large intraslab earthquake occurs just below the nucleation depth of an interplate earthquake. It seems to be difficult to explain the Mogi's observations by the present model of the induced aseismic frictional sliding by stress perturbations.

Lay et al. (1989) reported that tensional intermediate depth intraslab earthquakes usually occur and compressional ones are relatively quiescent before the occurrence of a large interplate earthquake at subduction zones. This can be understood by that the intraslab compressional stress is decreased when a shallower part of plate interface is locked and a deeper part is creeping. However, the 1978 Miyagi-Oki interplate earthquake was preceded by two large compressional intraslab earthquakes of $\mathrm{M}=5.8,1977$, and $\mathrm{M}=6.7$, 1978 (Takagi, 1980; Choy and Boatwright, 1982). The 2003 Miyagi-Oki compressional intraslab earthquake $(\mathrm{M}=7.1)$ followed a $\mathrm{M}=6.3$ shallow interplate earthquake (Fig. 1), which was accompanied by siginificant postseismic sliding (Miura et al., 2003). This interplate earthquake and postseismic sliding should cause compressional stress in the slab, possibly promoting the occurrence of the compressional intraslab earthquake (Kato and Hirasawa, 1999). This suggests that stress perturbations due to aseismic sliding and interactions between interplate earthquakes and intraslab earthquakes are important for earthquake occurrence.
Finally, I discuss a possible effect of the May, 2003, Miyagi-Oki intraslab earthquake on the next Miyagi-Oki interplate earthquake. About 1 year before the occurrence of the 1978 Miyagi-Oki interplate earthquake, a M = 5.8 intraslab earthquake occurred just below the source area of the interplate earthquake. The location of the $\mathrm{M}=5.8$ earthquake corresponds to those of Cases 1-3 in the present model, and the present simulation result suggests that the intraslab earthquake might promote the occurrence of the 1978 Miyagi-Oki interplate earthquake. Case 1 of the present 2D model resembles the 2003 Miyagi-Oki intraslab earthquake, and the simulation result suggests that the next interplate earthquake occurs about 0.5 year later from the occurrence of the intraslab earthquake. However, the present model is simplified too much to apply directly to the real Miyagi-Oki case. Firstly, the 2003 intraslab earthquake was not located at a simply deeper extension of the hypothetical source area of the Miyagi-Oki interplate earthquake but it is about 30 $\mathrm{km}$ distant in the direction parallel to the trench axis from the deeper extension of the epicenter of the 1978 MiyagiOki interplate earthquake (Fig. 1). The February 1978 intraslab earthquake of $\mathrm{M}=6.7$ was not located at a simply deeper extension of the June 1978 interplate earthquake of $\mathrm{M}=7.4$, either. Accordingly, the stress changes due to the intraslab earthquakes at the nucleation area of the interplate earthquake are significantly smaller than those for Case 1. Moreover, the three-dimensional location of the interplate earthquake relative to the intraplate earthquake significantly affects the pattern of stress changes. Rigorously speaking, 2D model is not appropriate for the 2003 intraslab earthquake or the February 1978 intraslab earthquake but it seems to work for the relation between the 1978 MiyagiOki interplate earthquake and the 1977 intraslab earthquake. Secondary, the rupture of the interplate earthquake starts near the deeper end of the seismogenic zone with velocityweakening frictional property in the present model. In the 1978 Miyagi-Oki interplate earthquake, the rupture started in a shallower part of the source area as shown in Fig. 1 (e.g., Seno et al., 1980; Yamanaka and Kikuchi, 2004), and therefore the stress perturbations near the deeper end of the seismogenic zone due to the intraslab earthquake may have little effect. Since nonuniformity in frictional property on the plate interface may affect the rupture initiation point (Kato and Seno, 2003), nonuniformity should be taken into consideration in future studies for more precise forecast. Thirdly, Yamanaka and Kikuchi (2004) determined the source area of the 1936 Miyagi-Oki earthquake, which was regarded as the same type earthquake as the 1978 Miyagi-Oki interplate earthquake when the recurrence model of Miyagi-Oki earthquakes was established (Earthquake Research Committee, 2000), to be different from that of the 1978 Miyagi-Oki interplate earthquake. This suggests that the average recurrence interval of 37.1 years estimated for the Miyagi-Oki interplate earthquakes, which is assumed in the present model, is questionable. Thus the present model may be too simple to apply to the forecast of the next Miyagi-Oki earthquake. A model with two-dimensional plate interface with nonuniform frictional property that can explain the source processes of both the 1936 and 1978 Miyagi-Oki earthquakes and precise earthquake history are required for a realistic forecast. 
Acknowledgments. I am grateful to S. Toda and an anonymous reviewer for their critical comments, which are helpful for improving the manuscript. I thank Y. Yamanaka for providing me of the original of Fig. 1. I used the computer system of the Earthquake Information Center of Earthquake Research Institute, University of Tokyo.

\section{References}

Aida, I., Numerical experiments for the tsunami accompanying the Miyagioki earthquake of 1978, Bull. Earthq. Res. Inst., Univ. Tokyo, 53, 1167 1175, 1978 (in Japanese with English abstract).

Blanpied, M. L., D. A. Lockner, and J. D. Byerlee, Frictional slip of granite at hydrothermal conditions, J. Geophys. Res., 100, 13045-13064, 1995.

Choy, G. L. and J. Boatwright, Broadband analysis of the extended foreshock sequence of the Miyagi-Oki earthquake of 12 June 1978, Bull Seismol. Soc. Am., 72, 2017-2036, 1982.

Dieterich, J. H., Modeling of rock friction 1. Experimental results and constitutive equations, J. Geophys. Res., 84, 2161-2168, 1979.

Dieterich, J. H., Earthquake nucleation on faults with rate- and statedependent strength, Tectonophysics, 211, 115-134, 1992.

Earthquake Research Committee, Long-term Evaluation of the Earthquakes off the Coast of Miyagi Prefecture, The Headquarters for Earthquake Research Promotion, 2000 (in Japanese).

Heki, K., S. Miyazaki, and H. Tsuji, Silent fault slip following an interplate thrust earthquake at the Japan trench, Nature, 386, 595-598, 1997.

Kato, N. and T. Hirasawa, The variation of stresses due to aseismic sliding and its effect on seismic activity, Pure Appl. Geophys., 155, 425-442, 1999.

Kato, N. and T. Hirasawa, Effect of a large outer rise earthquake on seismic cycles of interplate earthquakes: A model study, J. Geophys. Res., 105, 653-662, 2000.

Kato, N. and T. Seno, Hypocenter depths of large interplate earthquakes and their relation to seismic coupling, Earth Planet. Sci. Lett., 210, 53-63, 2003.

Kato, N. and T. E. Tullis, A composite rate- and state-dependent law for rock friction, Geophys. Res. Lett., 28, 1103-1106, 2001.

Kato, N. and T. E. Tullis, Numerical simulation of seismic cycles with a composite rate- and state-dependent friction law, Bull. Seismol. Soc. Am. 93, 841-853, 2003.

Kawakatsu, $H$. and T. Seno, Triple seismic zone and the regional variation of seismicity along the northern Honshu arc, J. Geophys. Res., 88, 42154230, 1983

King, G. C. P. and M. Cocco, Fault interaction by elastic stress changes: New clues from earthquake sequences, Adv. Geophys., 44, 1-38, 2001.

Kuroki, H., H. M. Ito, and A. Yoshida, A 3-D simulation of crustal deformation accompanied by subduction in the Tokai region, central Japan, Phys. Earth Planet. Inter., 132, 39-58, 2002.

Lay, T., L. Astiz, H. Kanamori, and D. H. Christensen, Temporal variation of large intraplate earthquakes in coupled subduction zones, Phys. Earth Planet. Inter., 54, 258-312, 1989.

Marone, C., Laboratory-derived friction laws and their application to seismic faulting, Аnnu. Rev. Earth Planet. Sci., 26, 643-696, 1998.

Miura, S., Y. Suwa, T. Sato, K. Tachibana, and A. Hasegawa, Slow slip events on the plate boundary off Miyagi and Fukushima detected by GPS and strain measurements, Abstracts for the 2003 Joint Meeting of Earth and Planetary Science, D007-011, 2003.

Mogi, K., Relationship between shallow and deep seismicity in the western Pacific region, Tectonophysics, 17, 1-22, 1973.

Nishimura, T., S. Miura, K. Tachibana, K. Hashimoto, T. Sato, S. Hori, E.
Murakami, T. Kono, K. Nida, M. Mishina, T. Hirasawa, and S. Miyazaki, Distribution of seismic coupling on the subducting plate boundary in northeastern Japan inferred from GPS observations, Tectonophysics, 323, 217-238, 2000.

Okada, T. and A. Hasegawa, The M7.1 May 26, 2003 off-shore Miyagi prefecture earthquake in northeast Japan: Source process and aftershock distribution of an intra-slab event, Earth Planets Space, 55, 731-739, 2003.

Press, W. H., B. P. Flannery, S. A. Teukolsky, and W. T. Vetterling, Numerical Recipes, 2nd Ed., Cambridge Univ. Press, New York, 1992.

Rani, S. and S. J. Singh, Static deformation of a uniform half-space to a long dip-slip fault, Geophys. J. Int., 109, 469-476, 1992.

Rice, J. R., Spatio-temporal complexity of slip on a fault, J. Geophys. Res., 98, 9885-9908, 1993.

Ruina, A. L., Slip instability and state variable friction laws, J. Geophys. Res., 88, 10359-10370, 1983.

Seno, T., K. Shimazaki, P. Somerville, K. Sudo, and T. Eguchi, Rupture process of the Miyagi-Oki, Japan, earthquake of June 12, 1978, Phys. Earth Planet. Inter., 23, 39-61, 1980.

Seno, T., T. Sakurai, and S. Stein, Can the Okhotsk plate be discriminated from the North American plate?, J. Geophys. Res., 101, 11305-11315, 1996.

Shimazaki, K. and T. Nakata, Time-predictable recurrence model for large earthquakes, Geophys. Res. Lett., 7, 279-282, 1980.

Simpson, R. W., S. S. Schulz, L. D. Dietz, and R. O. Burford, The response of creeping parts of the San Andreas fault to earthquakes on nearby faults: Two examples, Pure Appl. Geophys., 126, 665-685, 1988.

Stein, R. S., A. A. Barka, and J. H. Dieterich, Progressive failure on the North Anatolian fault since 1939 by earthquake stress triggering, Geophys. J. Int., 128, 594-604, 1997.

Stuart, W. D., Forecast model for great earthquakes at the Nankai trough subduction zone, Pure Appl. Geophys., 126, 619-641, 1988.

Takagi, A., Concluding remarks and precursory seismic activity of the 1978 Miyagi-oki earthquake, Proceedings of Earthquake Prediction Research Symposium, Seismological Society of Japan and Subcommittee of Earthquake Prediction, National Committee of Geophysics, Science Council of Japan, 231-241, 1980 (in Japanese).

Thurber, C. and R. Sessions, Assesment of creep events as potential earthquake precursors: Application to the creeping section of the San Andreas fault, California, Pure Appl. Geophys., 152, 685-705, 1998.

Toda, S., R. S. Stein, and T. Sagiya, Evidence from the AD 2000 Izu Islands swarm that stressing rate governs seismicity, Nature, 419, 58-61, 2002.

Toda, S., A. Oncel, and H. Horikawa, Seismicity rate changes associated with the May 26, 2003 Miyagiken-oki-no earthquake, Programme and Abstracts, Fall Meeting, Seism. Soc. Japan, A089, 2003.

Tse, S. T. and J. R. Rice, Crustal earthquake instability in relation to the depth variation of frictional slip properties, J. Geophys. Res., 91, 94529472, 1986.

Ueda, H., M. Ohtake, and H. Sato, Afterslip of the plate interface following the 1978 Miyagi-oki, Japan, earthquake, as revealed from geodetic measurement data, Tectonophysics, 338, 45-57, 2001.

Yamanaka, Y. and M. Kikuchi, The Miyagi-Oki earthquake on May 26, 2003, EIC Earthquake Note, 135, 2003.

Yamanaka, Y. and M. Kikuchi, Asperity map along the subduction zone in northeastern Japan inferred from regional seismic data, J. Geophys. Res. 2004 (in press).

N. Kato (e-mail: nkato@eri.u-tokyo.ac.jp) 